Президент России В.В. Путин неоднократно подчеркивал необходимость воспитания здорового поколения, любящего физкультуру и спорт, стремящегося к победам, способного бороться за интересы страны.

Журнал «Власть» продолжает публикацию статей видных специалистов в области спортивного карате. Этот вид спорта в августе 2016 г. был включен в программу летних Олимпийских игр 2020 г. в Токио. Учитывая возросшую конкуренцию в отечественном и международном спорте, необходимо совершенствовать подготовку спортсменов высокой квалификации, которая позволит им достичь высших результатов на крупнейших спортивных соревнованиях. Победы российских спортсменов, в т.ч. в Олимпийском движении, способствуют формированию имиджа страны на мировой арене.

Авторы публикуемой статьи предлагают обратить особое внимание на технико-тактические аспекты в подготовке спортсменов, которые определяют дальнейшие направления и способы совершенствования соревновательных боев.

Редколлегия журнала «Власть»

ТОНОЯН Хорен Аветисович - доктор педагогических наук, профессор кафедры физической подготовки Московского университета МВД России им. В.Я. Кикотя (107061, Россия, г. Москва, Окружной пр., 4; professor-tonoyan@mail.ru)

ЧУРАКОВ Аркадий Анатольевич - полковник полиции, старший преподаватель кафедры физической подготовки Московского университета МВД России им. В.Я. Кикотя (107061, Россия, 2. Москва, Окружной пр., 4; annailovyou0551@rambler.ru)

КОРЖЕНЕВСКИЙ Александр Николаевич - кандидат педагогических наук, заведующий лабораторией Всероссийского научно-исследовательского института физической культуры и спорта (105005, Россия, г. Москва, Елизаветинский пер., 10; korzhen-a@таil.ru)

КЛЕНДАР Владимир Анатольевич, кандидат медицинских наук, ведущий научный сотрудник Всероссийского научно-исследовательского института физической культуры и спорта (105005, Россия, г. Москва, Елизаветинский пер., 10; bobz@rambler.ru)

РУССУ Ольга Николаевна - кандидат педагогических наук, доцент кафедры физической культуры Российского государственного аграрного университета - МСХА им. К.А. Тимирязева (127550, Россия, г. Москва, ул. Тимирязевская, 49; olga.nik.russu@таil.ru)

\title{
ФОРМИРОВАНИЕ ТАКТИКИ ПРОВЕДЕНИЯ СОРЕВНОВАТЕЛЬНОГО БОЯ С ПРЕДПОЛАГАЕМЫМ ПРОТИВНИКОМ (НА ОСНОВЕ АНАЛИЗА СОРЕВНОВАТЕЛЬНОЙ ДЕЯТЕЛЬНОСТИ В КАРАТЭ ШОТОКАН)
}

\footnotetext{
Аннотация. Рост популярности каратэ и возросшая конкуренция на российских и международных соревнованиях вызывают необходимость тщательного изучения технико-тактических особенностей ведения поединка.

Соревновательная деятельность в каратэ Шотокан предьявляет высокие требования к физической и технической подготовленности. Однако при равном уровне этих сторон подготовленности успеха в соревновательном поединке может добиться тот спортсмен, который имеет преимущество в тактическом мышлении. Разработка эффективных тактико-технических моделей ведения схватки против предполагаемых противников является важной задачей при подготовке спортсменов к ответственным соревнованиям.

Ключевые слова: тактико-технические структуры в каратэ, видеоанализ, соревновательная деятельность, моделирование, каратисты высокой квалификации
} 
Введение. Совершенствование индивидуализации тренировки для участия в ответственных соревнованиях является одной из актуальных проблем в процессе тренировки спортсменов высокой квалификации. При подготовке к ответственным соревнованиям, наряду с развитием наивысшего уровня физической, функциональной, психологической подготовленности в единоборствах, большое значение имеет достижение высокого уровня тактико-технической подготовленности. Изучение тактико-технических особенностей ведения поединка позволяет существенно повысить эффективность соревновательной деятельности [Алхасов 2012]. Специалисты каратэ основное внимание уделяют совершенствованию пространственно-временных и скоростно-силовых характеристик эффективного нанесения ударов руками и ногами и их комбинаций [Микрюков 2003]. Такой подход позволяет добиваться высших спортивных результатов отдельным наиболее одаренным спортсменам.

В условиях напряженного ведения боя на ответственных соревнованиях, когда претенденты на победу имеют приблизительно равный уровень двигательной и технической подготовки, достижение победы в поединке будет определяться владением тактическими средствами разрешения соревновательного конфликта [Павлов 2004; Тимертаев 2009]. Умение каратиста выбрать правильную стратегию поединка для конкретного соперника и умелого использования правильных тактических решений определяет успех в схватке [Чупахин и др. 2010].

В спортивной подготовке высококвалифицированных спортсменов каратэ Шотокан возникло противоречие, когда предполагаемые противники имеют индивидуальные тактические находки для достижения успеха и владеют этим арсеналом ведения боя, а тренеры не могут использовать их и включить в индивидуальную подготовку своих учеников в связи с отсутствием технологии тактического анализа, создания технико-тактических портретов предполагаемых противников.

Целью исследования является разработка эффективных тактико-технических моделей ведения поединка против предполагаемых соперников на основе анализа соревновательной деятельности в каратэ Шотокан на предсоревновательном этапе подготовки.

При обследовании высококвалифицированных единоборцев, специализирующихся в каратэ Шотокан (МС, МСМК, 22-27 лет) использовались такие методы, как педагогическое наблюдение, видеоанализ соревновательной деятельности, педагогический эксперимент, статистические методы исследования.

Результаты исследования. Анализ данных литературы выявил недостаточную разработанность вопросов, связанных с моделированием тактики ведения поединка на основе изучения соревновательной деятельности в каратэ Шотокан. Выявление наиболее эффективных способов реализации действий в спортивных поединках каратистов, т.е. моделирование технико-тактической подготовленности, позволит не только определить уровень мастерства, но и повысить эффективность управления процессом при подготовке спортсменов, а также определить дальнейшие направления и способы его совершенствования [Смирнов 2015]. В настоящее время установлены подходы к анализу поведения спортсменов в схватке и формированию у них умения анализировать поведение противников на соревнованиях. Для решения поставленной задачи в начале исследования было проведено комплексное педагогическое наблюдение и видеоанализ соревновательной деятельности единоборцев. Педагогические наблюдения использовались для анализа учебно-тренировочного процесса, для сравнения рекомендаций по тактико-технической подготовке спортсменов каратэ Шотокан и реальной работы тренеров. Видеозапись поединков 20 высо- 
коквалифицированных каратистов позволила составить общее представление о поведении спортсменов в схватках и провести детальный анализ соревновательной деятельности для определения тактико-технических характеристик ведущих спортсменов.

При видеоанализе нами использовался экспертный метод (метод компетентных судей) определения характера взаимодействия спортсменов в схватке. Эксперты проводили сравнительный анализ конфликтного взаимодействия противников и фиксировали их поведение с помощью выявления моделей тактико-технических структур и регистрации технических действий.

Для осуществления видеоанализа с экспертами была проведена предварительная работа. С каждым из экспертов проводилась идентификация тактикотехнических структур, представленных в концепции конфликтного взаимодействия спортсменов, с их личным опытом борьбы. Параллельно проводилось обсуждение основных тактико-технических структур в атакующей, контратакующей и защитной стратегиях. Эксперты имитировали выполнение тактикотехнических структур с помощью различной техники. Такая подготовка экспертов позволила сформировать у них общие представления о конфликтном взаимодействии спортсменов и в то же время уточнить индивидуальность восприятия поединка каждым экспертом.

Тактический видеоанализ проводился следующим образом:

- проводилось биомеханическое описание специальной терминологией технических действий сначала одного бойца, потом другого;

- попеременное описание действий бойцов, выявление причинного соотнесения временно́го и пространственного взаимодействия спортсменов;

- определение причинности выполнения предыдущих и последующих действий;

- определение причинности воздействия действий одного спортсмена на действия его противника и наоборот;

- осуществлялась фиксация изменения типов конфликтного взаимодействия: содействия, принятия, противодействия, взаимодействия и уклонения;

- проводился биомеханический анализ техники управляющих воздействий;

- осуществлялось процессуальное рассмотрение поведения спортсменов в схватке при определении ТТС: исходное положение, нейтральная ситуация, ситуация начала маневра, ситуация возможного поражения, ситуация атакующего старта, ситуация поражения;

- дистанционное рассмотрение: боевая, предударная, ударная дистанция;

- определение механизмов достижения успеха: при вариативности атак и защит поиск благоприятных ситуаций и создание препятствий; игры угроз, вызовов и финтов, игры выбора; провоцирование, управление реагированием атаковой и защитной заряженностью, снятием ожидания второго действия и т.Д.

- определение смысла тактических и технических действий в тактико-технических структурах [Малков 1998].

Основная задача видеоанализа заключалась в сборе информации о тактикотехнических структурах, применяющихся в каратэ Шотокан, и статистики технических действий, что дало возможность разрабатывать контрольные задания для определения умения выполнять тактико-технические структуры.

Проведение педагогического эксперимента было осуществлено в ходе международного учебно-тренировочного сбора Российской ассоциации каратэ Шотокан с 6 по 25 августа 2017 г. на базе детского оздоровительного лагеря «Восточный» при подготовке к ответственным соревнованиям 2017 г. Для экспериментальной группы педагогический эксперимент являлся формиру- 
ющим те навыки и умения, которые отсутствовали в начале эксперимента. Экспериментальная группа формировалась в количестве 8 чел. - спортсменов высшей квалификации.

Испытуемые группы в течение эксперимента освоили разработанное нами содержание на основе формирования тактических умений в применении действий нападения и обороны.

Выполнение заданий оценивалось по 5-балльной шкале.

В результате проведенных проверок (предварительной, итоговой и отсроченной) у высококвалифицированных спортсменов были определены специализированные умения применять тактику ведения боя с вероятностными противниками. В экспериментальной группе были получены данные, представленные в таблицах 1-3 (предварительная, итоговая и отсроченная проверки), в которых отображены полученные в ходе проверок оценки выполнения контрольных заданий и средние значения этих оценок в экспериментальной группе.

Для установления статистически значимых различий между полученными средними групповыми оценками выполнения четырех заданий в предварительной, итоговой и отсроченной проверке для внутригруппового сравнения при коррекции данных использовался однофакторный анализ. Статистическая обработка показателей соревновательной деятельности способствует выявлению новых способов детализации и дополнения результатов и интерпретации представленных данных [Пашкова 2015].

Результаты сравнения средних значений оценок, полученных в экспериментальной группе, при сравнении итогов предварительной, итоговой и отсроченной проверок, при проверке специализированных умений планировать тактику ведения боя с вероятностными противниками представлены в итоговых таблицах дисперсионного анализа (см. табл. 4-11).

Таблица 1

\section{Результаты предварительной проверки специализированных умений применять тактику ведения боя с вероятностными противниками у испытуемых экспериментальной группы}

\begin{tabular}{|c|c|c|c|c|}
\hline № п/п & $\begin{array}{c}\text { Умение разрушать } \\
\text { «раздергиванием» } \\
\text { ритм серии ударов } \\
\text { противника }\end{array}$ & $\begin{array}{c}\text { Умение } \\
\text { уходить с } \\
\text { линии атаки } \\
\text { с одно- } \\
\text { временным } \\
\text { ударом }\end{array}$ & $\begin{array}{c}\text { Умение раскрывать } \\
\text { поражаемую } \\
\text { поверхность с уходом } \\
\text { в сторону для удара в } \\
\text { голову }\end{array}$ & $\begin{array}{l}\text { Умение провоцировать } \\
\text { сближение на атаку для } \\
\text { ответной атаки ударом } \\
\text { коленом в туловище } \\
\text { после ухода в сторону }\end{array}$ \\
\hline 1 & 1 & 1,5 & 2,5 & 3 \\
\hline 2 & 2 & 2 & 2 & 4 \\
\hline 3 & 0,5 & 1,5 & 3 & 3,5 \\
\hline 4 & 1 & 2 & 2 & 3 \\
\hline 5 & 1,5 & 1 & 2,5 & 2 \\
\hline 6 & 2 & 1,5 & 3 & 3 \\
\hline 7 & 1 & 2 & 2 & 2,5 \\
\hline 8 & 0,5 & 2 & 2 & 2 \\
\hline $\begin{array}{c}\text { Среднее } \\
\text { значение }\end{array}$ & 1,19 & 1,69 & 2,38 & 2,88 \\
\hline
\end{tabular}


Таблица 2

Результаты итоговой проверки специализированных умений применять тактику ведения боя с вероятностными противниками у испытуемых экспериментальной группы

\begin{tabular}{|c|c|c|c|c|}
\hline № п/п & $\begin{array}{c}\text { Умение разрушать } \\
\text { «раздергиванием» } \\
\text { ритм серии ударов } \\
\text { противника }\end{array}$ & $\begin{array}{c}\text { Умение } \\
\text { уходить с } \\
\text { лияи атаки } \\
\text { средно- } \\
\text { ударом }\end{array}$ & $\begin{array}{c}\text { Умение раскрывать } \\
\text { поражаемую } \\
\text { поверхность с уходом } \\
\text { в сторону для удара в в } \\
\text { голову }\end{array}$ & $\begin{array}{c}\text { умение провоцировать } \\
\text { сблиение на атаку для } \\
\text { ответной атаки ударом } \\
\text { коленом в туловище } \\
\text { после ухода в сторону }\end{array}$ \\
\hline 1 & 4 & 3 & 5 & 5 \\
\hline 2 & 3 & 4 & 5 & 5 \\
\hline 3 & 4 & 3,5 & 3 & 5 \\
\hline 4 & 3,5 & 4 & 5 & 5 \\
\hline 5 & 3 & 3 & 5 & 5 \\
\hline 6 & 4 & 4 & 4 & 4 \\
\hline 7 & 4 & 3,5 & 5 & 4,75 \\
\hline 8 & 3,5 & 4 & 4 & \\
\hline $\begin{array}{c}\text { Среднее } \\
\text { 3начение }\end{array}$ & 3,63 & 3,63 & & 5 \\
\hline
\end{tabular}

Таблица 3

Результаты отсроченной проверки специализированных умений применять тактику ведения боя с вероятностными противниками у испытуемых экспериментальной группы

\begin{tabular}{|c|c|c|c|c|}
\hline $\begin{array}{l}\text { № } \\
\text { п/ா }\end{array}$ & $\begin{array}{c}\text { Умение разрушать } \\
\text { «раздергиванием» } \\
\text { ритм серии ударов } \\
\text { противника }\end{array}$ & $\begin{array}{c}\text { Умение } \\
\text { уходить с } \\
\text { линии атаки } \\
\text { с одно- } \\
\text { временным } \\
\text { ударом }\end{array}$ & $\begin{array}{c}\text { Умение раскрывать } \\
\text { поражаемую } \\
\text { поверхность с уходом } \\
\text { в сторону для удара в } \\
\text { голову }\end{array}$ & $\begin{array}{c}\text { Умение провоцировать } \\
\text { сближение на атаку для } \\
\text { ответной атаки ударом } \\
\text { коленом в туловище } \\
\text { после ухода в сторону }\end{array}$ \\
\hline 1 & 5 & 5 & 5 & 5 \\
\hline 2 & 4 & 4 & 5 & 5 \\
\hline 3 & 4 & 5 & 5 & 5 \\
\hline 4 & 5 & 4 & 5 & 4 \\
\hline 5 & 5 & 4 & 5 & 5 \\
\hline 6 & 4 & 5 & 5 & 5 \\
\hline 7 & 5 & 5 & 5 & 5 \\
\hline 8 & 5 & 4 & 4 & 5 \\
\hline $\begin{array}{c}\text { Среднее } \\
\text { значение }\end{array}$ & 4,63 & 4,50 & 4,88 & 4,88 \\
\hline
\end{tabular}


Таблица 4

Результаты дисперсионного анализа предварительной и итоговой проверок умения разрушать «раздергиванием» ритм серии ударов противника в 1-м задании

\begin{tabular}{|c|c|c|c|c|}
\hline Вариация & $\begin{array}{c}\text { Сумма } \\
\text { квадратов }\end{array}$ & $\begin{array}{l}\text { Степень } \\
\text { свободы }\end{array}$ & Дисперсия & F-критерий \\
\hline Общая & 27,6 & 15 & 1,84 & \multirow{2}{*}{$\mathrm{F}_{\text {табл. }}=12,25(\mathrm{P} \geqslant 0,05)$} \\
\hline Внутригрупповая & 1,23 & 7 & 0,18 & \\
\hline Межгрупповая & 23,77 & 1 & 23,77 & \multirow{2}{*}{$F_{\text {расч. }}=63,75$} \\
\hline Остаточная & 2,61 & 7 & 0,37 & \\
\hline
\end{tabular}

Таблица 5

Результаты дисперсионного анализа предварительной и итоговой проверок умения уходить с линии атаки с одновременным ударом во 2-м задании

\begin{tabular}{|c|c|c|c|c|}
\hline Вариация & $\begin{array}{c}\text { Сумма } \\
\text { квадратов }\end{array}$ & $\begin{array}{l}\text { Степень } \\
\text { свободы }\end{array}$ & Дисперсия & F-критерий \\
\hline Общая & 17,36 & 15 & 1,16 & \multirow{2}{*}{$\mathrm{F}_{\text {табл. }}=12,25(\mathrm{P} \geqslant 0,05)$} \\
\hline Внутригрупповая & 1,98 & 7 & 0,28 & \\
\hline Межгрупповая & 15,01 & 1 & 15,01 & \multirow{2}{*}{$F_{\text {расч. }}=292,48$} \\
\hline Остаточная & 0,36 & 7 & 0,05 & \\
\hline
\end{tabular}

Таблица 6

Результаты дисперсионного анализа предварительной и итоговой проверок умения раскрывать поражаемую поверхность с уходом в сторону для удара в голову в 3-м задании

\begin{tabular}{|c|c|c|c|c|}
\hline Вариация & $\begin{array}{c}\text { Сумма } \\
\text { квадратов }\end{array}$ & $\begin{array}{l}\text { Степень } \\
\text { свободы }\end{array}$ & Дисперсия & F-критерий \\
\hline Общая & 23,44 & 15 & 1,56 & \multirow{2}{*}{$\mathrm{F}_{\text {табл. }}=12,25(\mathrm{P} \geqslant 0,05)$} \\
\hline Внутригрупповая & 1,19 & 7 & 1,17 & \\
\hline Межгрупповая & 18,06 & 1 & 18,06 & \multirow{2}{*}{$\mathrm{F}_{\text {расч. }}=30,19$} \\
\hline Остаточная & 4,19 & 7 & 0,6 & \\
\hline
\end{tabular}


Таблица 7

Результаты дисперсионного анализа предварительной и итоговой проверок умения провоцировать сближение на атаку для ответной атаки ударом коленом в туловище после ухода в сторону в 4-м задании

\begin{tabular}{|c|c|c|c|c|}
\hline Вариация & $\begin{array}{c}\text { Сумма } \\
\text { квадратов }\end{array}$ & $\begin{array}{l}\text { Степень } \\
\text { свободы }\end{array}$ & Дисперсия & F-критерий \\
\hline Общая & 18,9436 & 15 & 1,26 & \multirow{2}{*}{$\mathrm{F}_{\text {табл. }}=12,25(\mathrm{P} \geqslant 0,05)$} \\
\hline Внутригрупповая & 2,68 & 7 & 0,38 & \\
\hline Межгрупповая & 14,06 & 1 & 14,06 & \multirow{2}{*}{$\mathrm{F}_{\text {pacч. }}=45$} \\
\hline Остаточная & 2,19 & 7 & 0,31 & \\
\hline
\end{tabular}

Таблица 8

Результаты дисперсионного анализа итоговой и отсроченной проверок умения разрушать «раздергиванием» ритм серии ударов противника в 1-м задании

\begin{tabular}{|c|c|c|c|c|}
\hline Вариация & $\begin{array}{c}\text { Сумма } \\
\text { квадратов }\end{array}$ & $\begin{array}{l}\text { Степень } \\
\text { свободы }\end{array}$ & Дисперсия & F-критерий \\
\hline Общая & 7,25 & 15 & 0,48 & \multirow{2}{*}{$\mathrm{F}_{\text {табл. }}=12,25(\mathrm{P}=0,05)$} \\
\hline Внутригрупповая & 1,5 & 7 & 0,21 & \\
\hline Межгрупповая & 4 & 1 & 4 & \multirow{2}{*}{$\mathrm{F}_{\text {расч. }}=16$} \\
\hline Остаточная & 1,75 & 7 & 0,25 & \\
\hline \multicolumn{5}{|c|}{ Степень влияния фактора $-55,17 \%$} \\
\hline
\end{tabular}

Таблица 9

Результаты дисперсионного анализа итоговой и отсроченной проверок умения уходить с линии атаки с одновременным ударом во 2-м задании

\begin{tabular}{|c|c|c|c|c|}
\hline Вариация & $\begin{array}{c}\text { Сумма } \\
\text { квадратов }\end{array}$ & $\begin{array}{l}\text { Степень } \\
\text { свободы }\end{array}$ & Дисперсия & F-критерий \\
\hline Общая & 6,43 & 15 & 0,43 & \multirow{2}{*}{$\mathrm{F}_{\text {табл. }}=12,25(\mathrm{P}=0,05)$} \\
\hline Внутригрупповая & 1,19 & 7 & 0,17 & \\
\hline Межгрупповая & 3,06 & 1 & 3,06 & \multirow{2}{*}{$\mathrm{F}_{\text {расч. }}=9,8$} \\
\hline Остаточная & 2,19 & 7 & 0,31 & \\
\hline
\end{tabular}

\section{Выводы.}

1. Проведенный литературный обзор научно-методических материалов по спортивным единоборствам позволил установить актуальность разработки технологии определения тактико-технических характеристик предполагаемых противников и создания на ее основе типовых моделей их поведения в поединке. 
Таблица 10

Результаты дисперсионного анализа итоговой и отсроченной проверок умения раскрывать поражаемую поверхность с уходом в сторону для удара в голову в 3-м задании

\begin{tabular}{|c|c|c|c|c|}
\hline Вариация & $\begin{array}{c}\text { Сумма } \\
\text { квадратов }\end{array}$ & $\begin{array}{l}\text { Степень } \\
\text { свободы }\end{array}$ & Дисперсия & F-критерий \\
\hline Общая & 5,44 & 15 & 0,36 & \multirow{2}{*}{$\mathrm{F}_{\text {табл. }}=12,25(\mathrm{P}=0,05)$} \\
\hline Внутригрупповая & 2,94 & 7 & 0,42 & \\
\hline Межгрупповая & 0,56 & 1 & 0,56 & \multirow{2}{*}{$\mathrm{F}_{\text {расч. }}=2,03$} \\
\hline Остаточная & 1,94 & 7 & 0,28 & \\
\hline
\end{tabular}

Таблица 11

Результаты дисперсионного анализа итоговой и отсроченной проверок умения провоцировать сближение на атаку для ответной атаки ударом коленом в туловище после ухода в сторону ударом в 4-м задании

\begin{tabular}{|c|c|c|c|c|}
\hline Вариация & $\begin{array}{c}\text { Сумма } \\
\text { квадратов }\end{array}$ & $\begin{array}{l}\text { Степень } \\
\text { свободы }\end{array}$ & Дисперсия & F-критерий \\
\hline Общая & 2,44 & 15 & 0,16 & \multirow{2}{*}{$\mathrm{F}_{\text {табл. }}=12,25(\mathrm{P}=0,05)$} \\
\hline Внутригрупповая & 1,94 & 7 & 0,28 & \\
\hline Межгрупповая & 0,06 & 1 & 0,06 & \multirow{2}{*}{$\mathrm{F}_{\text {расч. }}=1$} \\
\hline Остаточная & 0,44 & 7 & 0,06 & \\
\hline
\end{tabular}

2. Тактическо-технический анализ позволил установить, что тактика ведения боя квалифицированным спортсменом каратэ Шотокан характеризуется применением разнообразных маневренных действий, угроз, ложных атак, имитаций атак, вызовов, провоцирований на преждевременные движения, что позволяет спортсменам создавать тактическое преимущество по дистанции, линии атаки, по ритму, по раскрытию ударных поверхностей. После проведения педагогического моделирования на основе тактического анализа нами были разработаны 4 тактико-технические структуры против 4 типов предполагаемых противников.

Против спортсменов, стремящихся достигнуть победы силовыми ударами (модель 1), применяются атаки с нарушением ритма ударов в серии «раздергиванием» импульсами начала удара перед завершающим ударом в туловище.

Против спортсменов, стремящихся достигнуть победы темповыми ударами (модель 2) применяются атаки с уходом с линии удара с одновременным ударом в туловище противника.

Против спортсменов, стремящихся достигнуть победы за счет управления двигательными реагированиями противника (модель 3) или использования комбинационного нападения (модель 4), применяются защиты уходом боковым маневром по диагонали назад и возвращением для выполнения ответной атаки ударами в голову ногой или в туловище коленом. 
4. Для улучшения быстроты реагирования в типовых ситуациях целесообразно используемые спортсменом преднамеренные действия автоматизировать и освоить их применение на момент возникновения благоприятной ситуации при распознавании предсигналов действий возможных противников.

5. Педагогический эксперимент подтвердил выдвинутую гипотезу об эффективности разработанного нами содержания одного из основных разделов тактической подготовки, овладения спортсменами каратэ Шотокан тактическими умениями планировать ведение боев с вероятными противниками и применять тактико-технические структуры в соответствии с типовыми моделями поведения предполагаемых противников.

\section{Список литературы}

Алхасов Д.С. 2012. Структура технической подготовки в каратэ. - Теория и практика физической культуры. № 7. С. 75-77.

Малков О.Б. 1998. Тактический видеоанализ конфликтного поведения единоборцев в соревновательных схватках. - Тхэквондо: сборник научных статей. М.: Изд-во РГАФК. С. 62-65.

Микрюков В.Ю. 2003. Каратэ: пособие для студентов высших учебных заведений. М.: ИЦ «Академия». 240 с.

Павлов С.В. 2004. Комплексный контроль состояния спортивной подготовленности в процессе соревновательной деятельности единобориев: автореф. дис. ... д.пед.н. Тюмень. 40 с.

Пашкова У.Ю. 2015. Опыт использования статистического анализа характеристик соревновательной деятельности в системе подготовки каратистов. Физическое воспитание и спортивная тренировка. Волгоград. № 4(14). С. 36-41.

Смирнов Ю.А. 2015. Благоприятная динамическая ситуация как фактор эффективной атаки в карате. - Ученые записки университета им. П.Ф. Лесгафта. № 4(122). С. 179-183.

Тимертаев О.М. 2009. Модель технико-тактической подготовленности высококвалифицированных каратистов. - Теория и практика физической культуры. № 4. С. 70-75.

Чупахин А.А., Кошелев О.П., Ветчинова Т.С., Пашкова У.Ю. 2010. Обучение каратэ на различных этапах подготовки: программно-методическое пособие; адаптированная учебная программа дополнительного образования детей. Орел. $89 \mathrm{c.}$

TONOYAN Khoren Avetisovich, Dr.Sci. (Ped.Sci.), Professor of the Chair of Physical Training, V.Ya. Kikot' Moscow University of the Ministry of Internal Affairs of the Russian Federation (4 Okruzhnoy Pass, Moscow, Russia, 107061; professor-tonoyan@mail.ru)

CHURAKOV Arkadiy Anatol'evich, Colonel of the Police, Senior Lecturer of the Chair of Physical Training, V.Ya Kikot' Moscow University of the Ministry of Internal Affairs of the Russian Federation (4 Okruzhnoy Pass, Moscow, Russia, 107061; annailovyou0551@rambler.ru)

KORZHENEVSKY Aleksandr Nikolaevich, Cand.Sci. (Ped.Sci.), Head of the Laboratory, All-Russian Scientific Research Institute of Physical Culture and Sport (10 Elizavetinsky Lane, Moscow, Russia, 105005; korzhen-a@mail.ru) KLENDAR Vladimir Anatol'evich, Cand.Sci. (Med.Sci.), Leading Researcher of the All-Russian Scientific Research Institute of Physical Culture and Sport (10 Elizavetinsky Lane, Moscow, Russia, 105005; bobz@rambler.ru)

RUSSU Olga Nikolaevna, Cand.Sci. (Ped.Sci.), Associate Professor of the Chair of Physical Culture, Russian State Agrarian University - Moscow Timiryazev Agricultural Academy (49 Timiryazevskaya St, Moscow, Russia, 127550; olga. nik.russu@mail.ru) 


\title{
FORMATION OF THE TACTICS OF CONDUCTING A COMPETITIVE BATTLE WITH AN ALLEGED ENEMY (BASED ON THE ANALYSIS OF COMPETITIVE ACTIVITIES IN KARATE SHOTOKAN)
}

\begin{abstract}
The growing popularity of karate and increased competition in Russian and international tournaments make it necessary to study the technical and tactical characteristics of the fight. Competitive activity in karate Shotokan makes high demands on physical and technical preparedness. However, with an equal level of these sides, the athlete who has an advantage in tactical thinking can achieve success in a competitive duel. The development of effective tactical and technical models of conducting a fight against alleged opponents is an important task in training athletes for responsible competitions. Keywords: tactical and technical structures in karate, video analysis, competitive activity, modeling, karate athletes of high qualification
\end{abstract}

РУССУ Ольга Николаевна - кандидат педагогических наук, доцент кафедры физической культуры Российского государственного аграрного университета - МСХА им. К.А. Тимирязева (127550, Россия, г. Москва, ул. Тимирязевская, 49; olga.nik.russu@таil.ru)

\section{ОРГАНИЗАЦИОННО-УПРАВЛЕНЧЕСКАЯ МОДЕЛЬ ФОРМИРОВАНИЯ ФИЗИЧЕСКОЙ КУЛЬТУРЫ ШКОЛЬНИКОВ: СОЦИАЛЬНЫЙ АСПЕКТ}

\begin{abstract}
Аннотация. В работе представлены результаты социального эксперимента по формированию физической культуры школьников с учетом современных тенденций модернизации системы общего образования в условиях внедрения новых образовательных стандартов. Автор разработал организационноуправленческую модель формирования физической культуры школьников и выявил условия ее реализации.

Ключевые слова: физическая культура школьника, модернизация физкультурного образования, формирование универсальных учебных действий, компетентностный подход, организационно-управленческая модель, результаты обучения предмету «Физическая культура»
\end{abstract}

Введение. Физическая культура превратилась в XXI в. в глобальный социокультурный феномен. Формирование физической культуры человека происходит на основе неразрывного единства и гармонии физического (телесного, биологического) и духовного (социального) и начинается с детства.

Социальная значимость исследуемой проблемы нашла свое отражение в таких нормативных документах, как федеральный закон «О физической культуре и спорте в Российской Федерации» (2007), Федеральная программа развития физической культуры и спорта в Российской Федерации на период с 2006 до 2015 года, Стратегия развития физической культуры и спорта в РФ до 2020 года, в которых определены основные направления распространения стандартов здорового образа жизни и формирования физической культуры различных групп населения. Наши социологические исследования показали, что более половины опрошенных $(56,5 \%)$ стараются вести здоровый образ жизни, $18 \%$ не могут утверждать это, а 25,5\% затрудняются ответить.

Проблема исследования вытекает из необходимости создания качественно 